\title{
ANALISA SIMULASI PERFORMANSI KAMPAS REM KOMPOSIT DENGAN VARIASI BEBAN PEMODELAN METODE ELEMEN HINGGA
}

\author{
Suci N. Sandi ${ }^{1 *}$, Ikhwansyah Isranuri ${ }^{2}$, M. Sabri ${ }^{3}$, Farida Ariani ${ }^{4}$, Syahrul Abda ${ }^{5}$ \\ ${ }^{1,2,3,4,5}$ Departemen Teknik Mesin, Fakultas Teknik, Universitas Sumatera Utara \\ Email: Suci.nurliasandi97@gmail.com
}

\begin{abstract}
Abstrak
Rem merupakan salah satu faktor penting dalam sistem pengereman, karena pentingnya fungsi rem pada kendaraan perlu dilakukannya kajian mendalam tentang koefisien gesek, keausan dan tahaptahapnya. Simulasi dengan menggunakan metode elemen hingga (FEM) merupakan salah satu program untuk menentukan fenomena-fenomena yang terjadi pada suatu komponen. Dalam penelitian ini telah mensimulasikan gaya pengereman belakang (tromol) kendaraan sepeda motor. Metode yang digunakan adalah memodelkan gesekan pada proses pengereman. Analisa tersebut dilakukan dengan menggunakan simulasi program dengan metode elemen hingga (FEM) dalam bentuk pemodelan 3D. Material kampas rem adalah komposit (cangkangn kemiri,serat daun nenas, aluminium dan polyuretan). Karena proses pengereman dengan tekanan dan gaya momen yang berubah-ubah maka analisa dilakukan dengan analisa statis bertujuan untuk mendapatkan hasil deformasi dan von misses dan dinamis untuk mendapatkan hasil frictional stress, sliding distance dan pressure agar mendapatkan nilai koefisien gesek simulasi. Perubahan terjadi dengan memberikan variasi pembebanan dengan kecepatan konstan.
\end{abstract}

Kata kunci : Kampas rem, Komposit, Pembebanan, FEA, simulasi.

\section{Pendahuluan}

Sepeda motor merupakan hasil perkembangan teknologi yang membutuhkan banyak komponen dan jenis material. Komponennya meliputi komponen mesin, komponen casis, dan komponen kelistrikan. Komponen mesin meliputi piston, blok silinder poros engkol dan lain-lain..[1] Rem adalah suatu piranti untuk memperlambat atau menghentikan gerakan roda yang berputar. Gerak roda yang diperlambat otomatis gerak kendaraan menjadi lambat. Fungsi rem adalah menyerap baik energi kinetik dari bagian yang bergerak atau energi potensial yg ditimbulkan oleh komponen lain [2]. Rem tromol merupakan sistem rem yang telah menjadi metode pengereman standar yang digunakan sepeda motor kapasitas kecil pada beberapa tahun belakangan ini. Alasannya adalah karena rem tromol sederhana dan murah, konstruksi rem tromol umumnya terdiri dari komponen-komponen seperti: sepatu rem (brake shoe), tromol (drum), pegas pengembali (return springs), tuas penggerak (lever), dudukan rem tromol (backplate), dan cam/nok penggerak. Cara pengoperasian rem tromol pada umumnya secara mekanik yang terdiri dari; pedal rem (brakepedal) dan batang (rod) penggerak [3].

Tujuan Untuk mengetahui tegangan (Equivalen stress von-misses) yang terjadi pada kampas rem komposit melalui simulasi mengetahui total deformasi yang terjadi pada kampas rem komposit dengan melalui simulasi untuk mengetahui nilai koefisien 
gesek pada kampas rem komposit yang didapat dari hasil simulasi software ansys membandingkan nilai koefisien gesek kampas rem kompositpada saat pengujian dengan nilai koefisien gesek pada simulasi.

\section{Metode}

Penelitian dilakukan di Laboratorium Noise and Vibration Center Magister Teknik Mesin USU. Objek simulasi yaitu Tromol dan kampas rem roda belakang sepeda motor menggunakan alat uji laju keausan.

\subsection{Disain bahan simulasi}

Kampas rem tersusun atas dua bagian yaitu sepatu rem dan kampas rem. Sepatu rem tersusun dari material komposit dengan material properties di dapat dari hasil pengujian sifat fisik dan mekanik, sedangkan untuk sepatu rem nya sendiri dari material Cast iron yang berstandart HGP (Honda genuin parts). Pada simulasi ini objek di disain menggunakan software Autocad 2013 3D Berikut ini gambar masing-masing komponen :
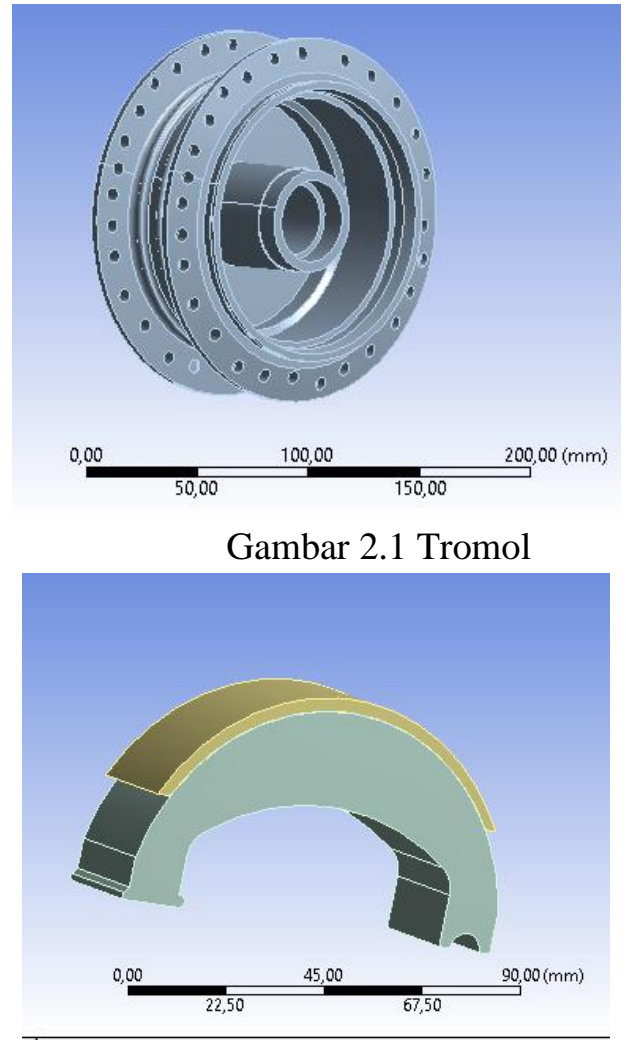

Gambar 2.2 Kampas rem 


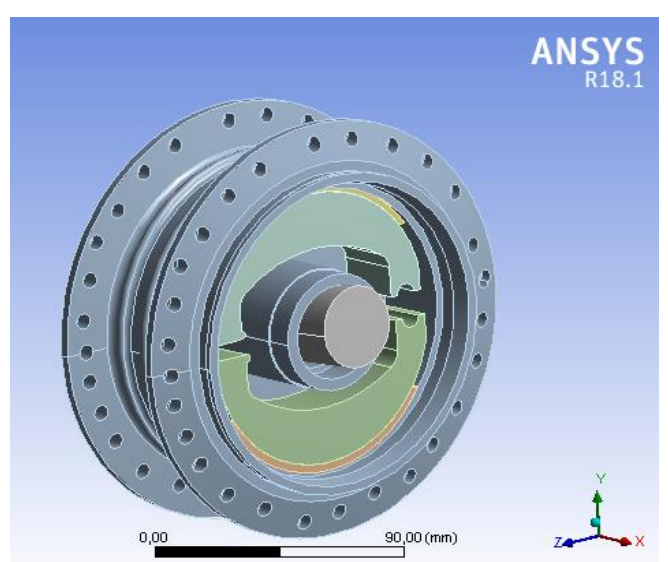

Gambar 2.3 Assembly Tromol

2.2 Material yang digunakan

Material yang dikembangkan pada penelitian ini material kampas rem yang terbuat dari bahan komposit yaitu cangkang kemiri, serat daun nenas, aluminium dan polyuretan sebagai perekatnya. Komposisi material pembentuk di ambil dari penelitian sebelumnya 70:30 yang telah dilakukan oleh Mahasiswa Pasca Sarjana Magister Teknik Mesin USU.

Tabel 2.1 Data material hasil pengujian

\begin{tabular}{|l|l|l|l|}
\hline Material & Density $\left(\mathrm{g} / \mathrm{cm}^{\wedge} 3\right)$ & Modulus Young $(\mathrm{Mpa})$ & Poisson Ratio \\
\hline Komposit & 1.677 & 9.9222 & 0,3 \\
\hline Cast Iron & 7.200 & 110000 & 0,28 \\
\hline
\end{tabular}

\subsection{Simulasi ansys workbench}

Pada penyelesaian simulasi menjelaskan langkah-langkah dalam menjalankan simulasi untuk mendapatkan hasil dari proses pengereman, berikut langkah-langkahnya:

2.3.1 Engineering data

Pada penelitian ini digunakan material baru yaitu cangkang kemiri, serat daun nanas, alumunium dan poliuretan yang belum terdaftar pada ansys workbench sehingga kita perlu memasukan data materialnya ke engineering data.

\subsubsection{Geometri}

Setelah melakukan engineering data, tahap atau langkah selanjutnya adalah melalukan pemodelan geometri. Hal ini dilakukan dengan cara klik ganda pada geometri lalu akan muncul jendela geometri.

\subsubsection{Model}

Setelah membuat atau mengimport geometri, tahap selanjutnya adalah melukan Model. Pada model input dan output data di masukkan ke dalam simulasi seperti pembebanan, kecepatan dan momen. 


\subsubsection{Meshing}

Mesh merupakan pembagian objek menjadi bagian yang lebih kecil. Semakin kecil meshing yang dibuat maka hasil perhitungan akan semakin teliti namun membutuhkan daya komputasi yang besar.

\subsubsection{Solution}

Tahap terakhir setelah menngatur jenis pembebanan dan fix support adalah Solution. Solution adalah proses analisa numerik yang dilakukan ansys untuk mendapatkan parameter yang diinginkan. Dalam penelitian ini, parameter yang ingin didapatkan adalah Total deformasi, equivalen stress von-misses, frictional stress, sliding distance dan preasurre yang terjadi pada kampas rem komposit.

\section{Hasil dan pembahasan}

Simulasi dilakukan dengan mengabaikan kondisi jalan dan permukaan jalan, menggunakan variasi beban yaitu $2 \mathrm{~kg}, 3 \mathrm{~kg}$, dan $4 \mathrm{~kg}$. Berikut ini akan di tampilkan beberapa hasil simulasi berupa deformasi total, equivalen stress, frictional stres, pressure dan sliding distance pada tromol dan kampas rem.

Pada simulasi ini di bagi menjadi dua yaitu simulasi statis untuk mencari besarnya tegangan dan deformasi yang terjadi pada kampas rem sedangkan simulasi dinamis digunakan untuk mencari besarnya koefisien gesek yang terjadi pada kampas rem dengan membandingkan berdasarkan hitungan eksperimental serta besarnya sliding distance yang terjadi pada kampas rem.

\subsection{Hasil simulasi statis (Static Structural)}

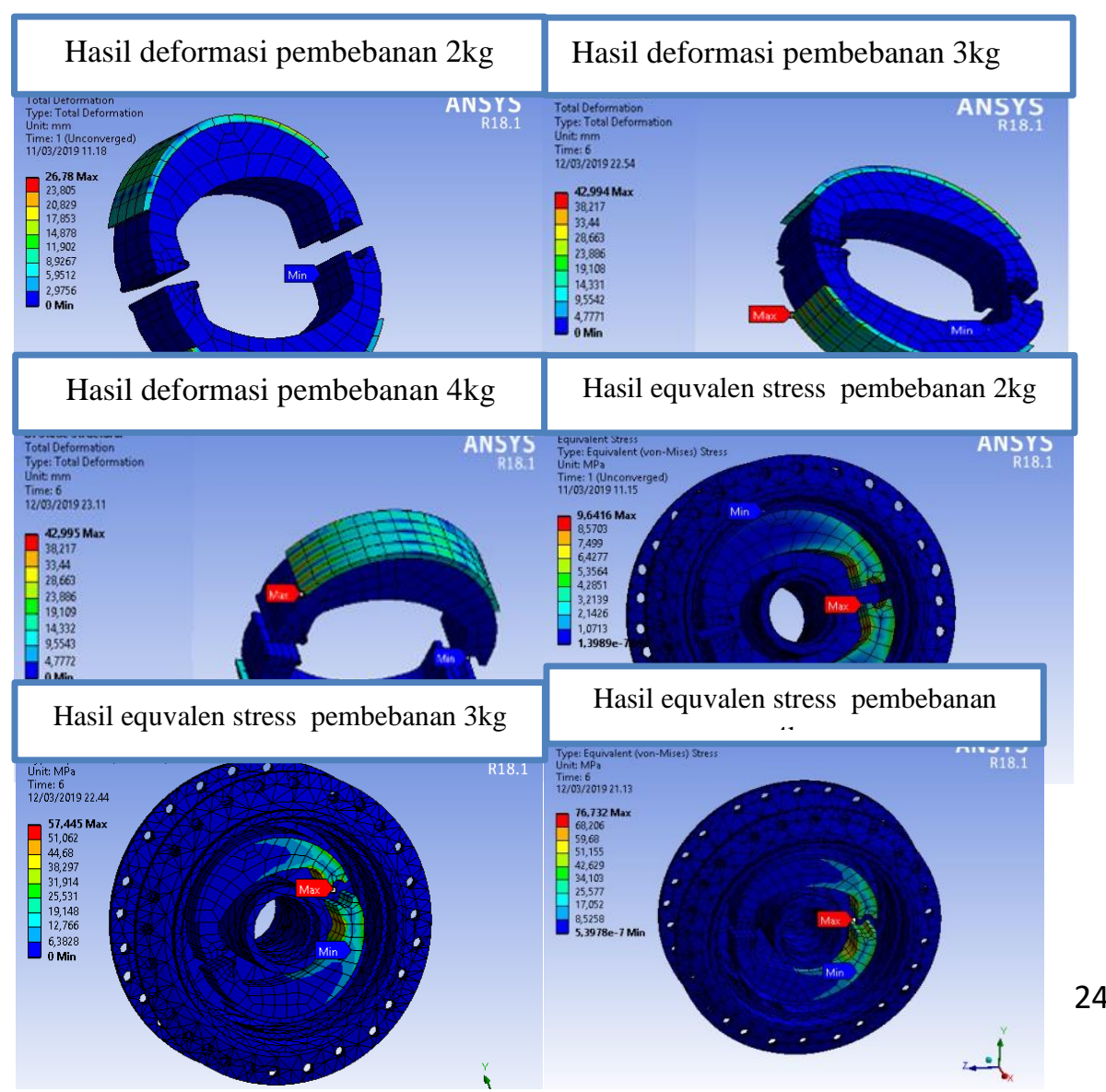


Gambar 3.1 Deformasi dan equivalen stress pada kampas rem

Hasil simulasi menunjukkan deformasi terbesar maksimum pada pembebanan 4 $\mathrm{kg}$ dengan nilai 42,995 $\mathrm{mm}$ dan untuk equivalen stress terbesar didapatkan pada pembebanan $4 \mathrm{~kg}$ dengan nilai sebesar 76,732 Mpa. Dapat disimpulkan bahwa semakain besar beban yang di terima kampas rem maka berbanding lurus dengan nilai deformasi dan equivalen stress yang besar pula.

\subsection{Hasil simulasi dinamis (Transient Structural)}

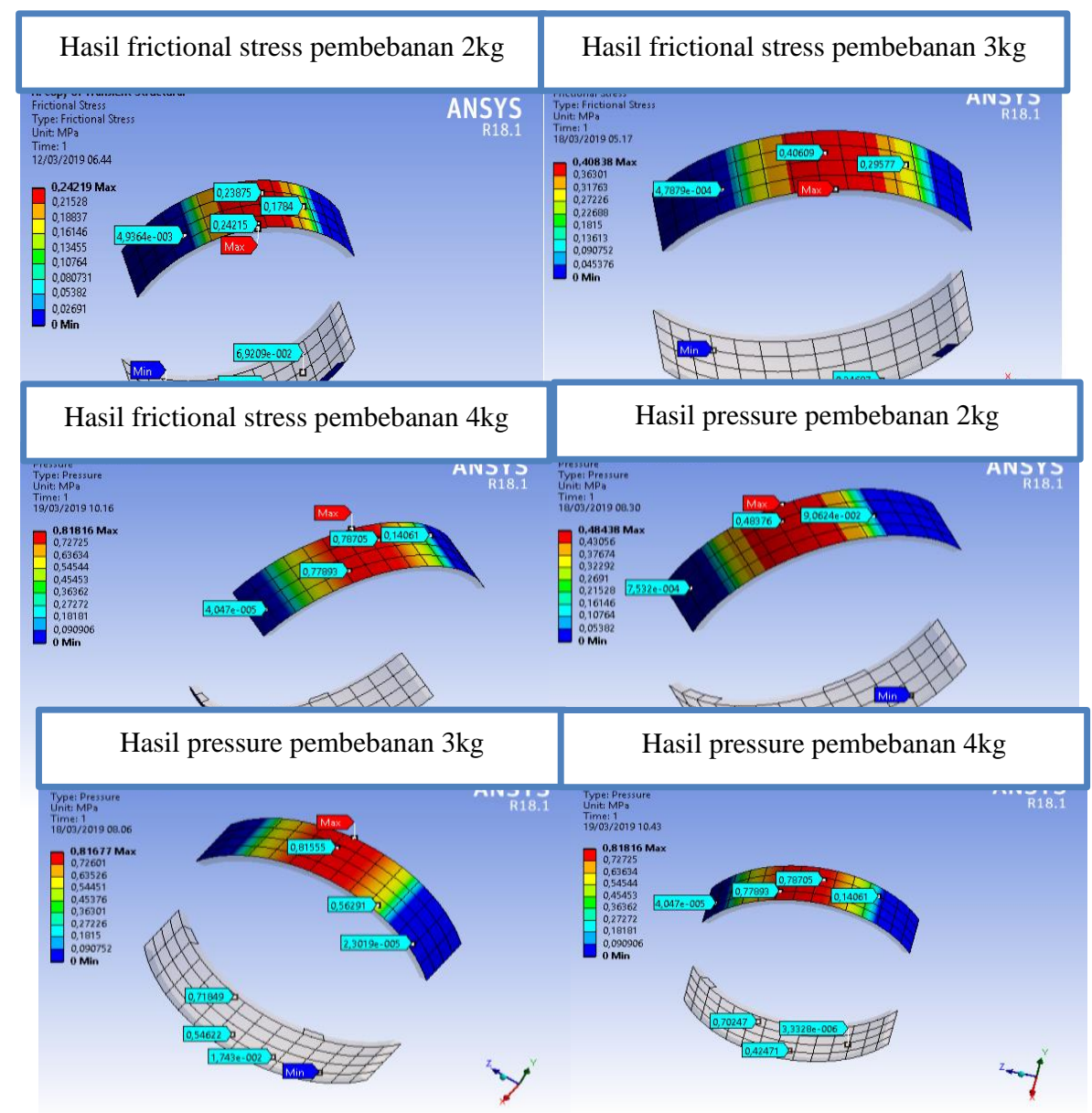

Gambar 3.2 frictional stress dan pressure pada permukaan kampas rem

Hasil simulasi menunjukkan bahwa tingkat tertinggi frictional stress pada pembebanan 4 $\mathrm{kg}$ dengan nilai maksimum sebesar 0,40908 Mpa. Sedangkan untuk nilai pressure terbasar pada pembebanan $4 \mathrm{~kg}$ dengan nilai $0.81816 \mathrm{Mpa}$.

3.3 Menghitung nilai koefisien gesek pada kampas rem

1. Nilai koefisien gesek eksperimental dan simulasi

Tabel 3.1 koefisien gesek eksperimental 


\begin{tabular}{|c|c|c|c|c|c|}
\hline $\begin{array}{l}\text { Pengujian } \\
\text { ke- }\end{array}$ & Beban (kg) & $\begin{array}{c}\mathrm{T} \\
\text { pengujian }\end{array}$ & T roda & $\mu$ & $\mu$ rata-rata \\
\hline 1 & 2 & 11,140 & 4,218 & 0,37 & \multirow{5}{*}{0,55} \\
\hline 2 & 2,5 & 12,6592 & 5,227 & 0,47 & \\
\hline 3 & 3 & 16,709 & 8,864 & 0,52 & \\
\hline 4 & 3,5 & 19,495 & 12,496 & 0,64 & \\
\hline 5 & 4 & 20,2547 & 17,791 & 0,79 & \\
\hline
\end{tabular}

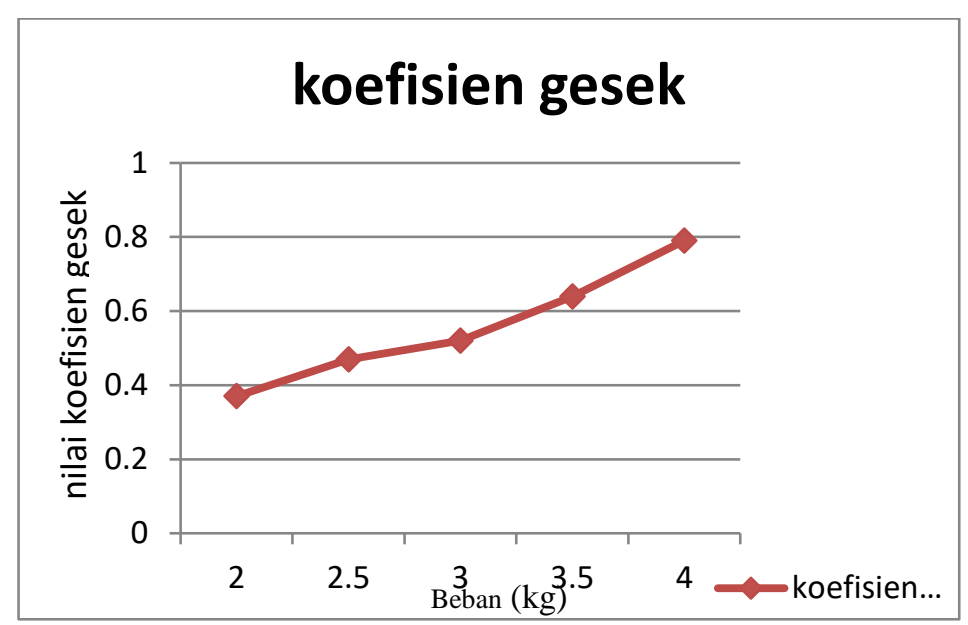

Gambar 3.3 Grafik koefisien gesek eksperimental

Tabel 3.2 Koefisien gesek simulasi

\begin{tabular}{cccccc|} 
ket & $\begin{array}{c}\text { Pembebanan } \\
(\mathrm{kg})\end{array}$ & $\tau_{f}(\mathrm{Mpa})$ & $\mathbf{P}(\mathrm{Mpa})$ & $\boldsymbol{\mu}$ & $\boldsymbol{\mu}$ rata-rata \\
\cline { 1 - 4 } $\mathbf{A}$ & 2 & 0,15691 & 0,3690 & 0,42 & \\
\cline { 1 - 4 } $\mathbf{B}$ & 3 & 0,236879 & 0,453759 & 0,52 & 0,50 \\
\cline { 1 - 4 } $\mathbf{C}$ & 4 & 0,257265 & 0,455306 & 0,56 & \\
\hline
\end{tabular}




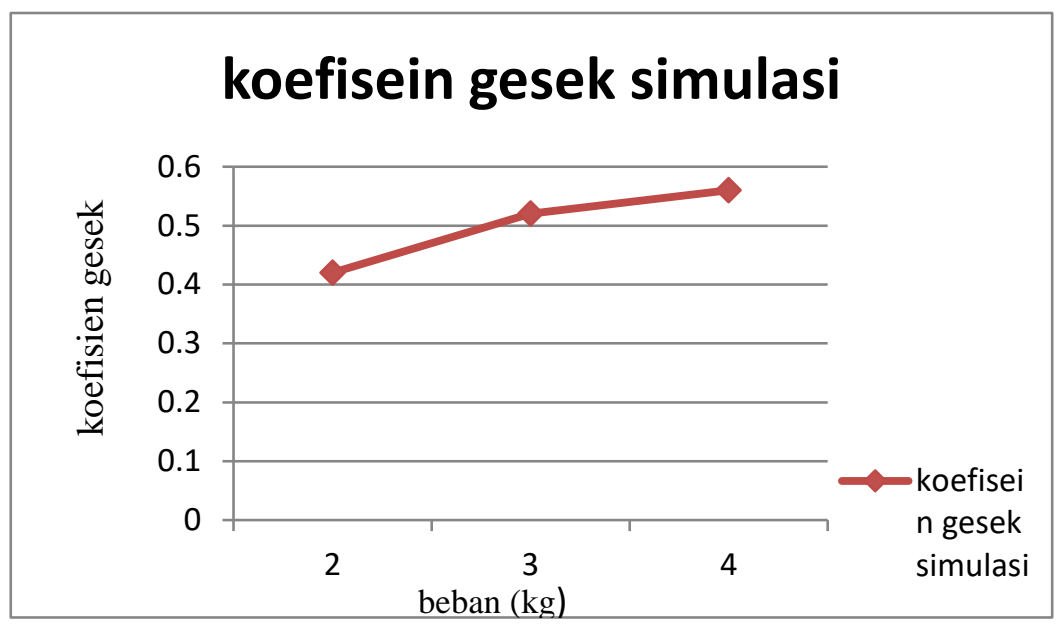

Gambar 3.4 Grafik koefisien gesek simulasi

\section{Kesimpulan}

Hasil simulasi didapatkan tegangan maksimum terjadi pada kampas rem dengan beban sebesar $4 \mathrm{~kg}$ nilai tegangan maksimum sebesar 76,732 Mpa dengan momen sebesar 405,1 N. Hasil simulasi membuktikan bahwa total deformasi maksimum sebesar 42,995 mm pada beban $4 \mathrm{~kg}$ dengan gaya sebesar 405,1 N. Pada permukaan kampas rem menunjukkan kontur warna yang berbeda akibat dari pembebanan kampas rem pada saat roda berputar. Pada hasil simulasi dengan percobaan gesek didapatkan nilai frictional stress dan pressure untuk menentukan koefisien gesek kampas rem komposit yaitu sebesar 0,50 dengan variasi beban $2 \mathrm{~kg}, 3 \mathrm{~kg}$ dan $4 \mathrm{~kg}$. Setelah menghitung nilai koefisien gesek dari hasil eksperimental dan membandingkan dengan hasil simulasi, maka didapatkan persen galat sebesar $9,09 \%$.

Referensi

[1] Sutikno. 2008. Pengaruh komposisi serbuk tempurung kelapa terhadap sifat- sifat fisik dan mekanik bahan gesek non asbes untuk aplikasi kampas rem sepeda motor. Semearang: Professional, Jurnal Ilmiah Popular dan Teknologi Terapan, vol.6 No. 2, hal. 893-904.

[2] K.M Jossy, 2011, Brake and Dynamometer, SSAS institute of technology.

[3] Sutantra, I Nyoman. 2001. Teknologi Otomotif, Teori dan Aplikasinya. Surabaya: Guna Widya 